\title{
Differentially expressed genes in a porcine adult hepatic stem-like cell line and their expression in developing and regenerating liver
}

\author{
Junko Kano ${ }^{1}$, Tadashi Ishiyama' ${ }^{1}$ Tatsuo lijima², Yukio Morishita ${ }^{3}$, Soichiro Murata ${ }^{4}$, Katsuji Hisakura ${ }^{4}$, \\ Nobuhiro Ohkohchi ${ }^{4}$ and Masayuki Noguchi ${ }^{1}$
}

To identify differentially expressed genes in adult hepatic stem cells, we performed suppression-subtractive hybridization (SSH) between adult porcine hepatic stem-like cells (HSLCs) and hepatocytes, and the expression of selected genes was assessed in porcine fetal livers and regenerating liver in an $80 \%$ hepatectomy model. SSH and subsequent differential screening selected 39 clones that were expressed differentially in HSLCs, including six known genes, 10 unknown genes, one unidentified gene and some chimeric fragments. Four of these genes showed significantly higher expression in HSLCs than in mature hepatocytes: anti-leukoproteinase, matrix Gla protein, amyloid- $\beta$ precursor protein (APP) and dickkopf-3 (DKK-3). Among them, the mRNA expression of APP and DKK-3 was significantly higher in fifth GW fetal liver than in seventh and thirteenth GW fetal and adult livers, unlike the expression patterns of $\alpha$-fetoprotein (AFP) or albumin. These mRNAs were detected in the parenchyma of fifth GW fetal liver, whereas in normal adult liver possible expression was limited to the periportal area. On the other hand, immunohistochemistry, Masson's trichrome staining and silver impregnation demonstrated APP and DKK-3 proteins in fifth GW fetal liver in which intralobular bile ducts and hepatic plates had not completely developed. DKK-3 and AFP mRNAs were upregulated on the seventh day (7D) after 80\% hepatectomy. In the liver tissue, DKK-3 and AFP proteins were detected in mesenchymal cells in the periportal area and parenchyma, respectively. These data for DKK-3 expression in adult livers suggest the possible presence of adult HSLCs in the periportal area. The pattern of histological staining suggested that 7D liver was in the process of regeneration, showing a character similar to the fifth GW fetal liver. It is speculated that DKK-3 is upregulated in immature and developing livers, and has possible involvement in hepatic differentiation and liver regeneration.

Laboratory Investigation (2008) 88, 132-143; doi:10.1038/labinvest.3700709; published online 3 December 2007

KEYWORDS: adult stem cells; fetal; gene expression; hepatic stem cells; hepatocytes; regeneration

It has been demonstrated that the adult liver has stem-like cells or progenitor cells, which are considered to have possible involvement in liver carcinogenesis and regeneration. Some phenotypes of hepatic stem-like cells (HSLCs), including oval cells and small hepatocytes, have been isolated from adult liver and their properties studied. ${ }^{1-4}$ The results have suggested that HSLCs show different phenotypes at each stage of differentiation. The expression profiles and markers of HSLCs have also been investigated. Oval cells express immature hematopoietic cell markers in addition to markers of cholangiocytes and hepatoblasts. ${ }^{5,6}$ On the other hand, hepatoblasts are considered to be equivalent to hepatic stem cells (HSCs) in embryonic liver, and their marker molecules and mechanism of differentiation have been investigated extensively. Dlk (also known as Pref-1) and hematopoietic lineage markers such as c-kit and c-met have been used to isolate hepatoblasts. ${ }^{7,8}$ Thus, although it has been revealed that oval cells and hepatoblasts express some marker molecules that play a role during the developmental and immature stages, the features of adult HSCs have not been well established, and their function in liver regeneration and mechanism of differentiation remain unclear. From the

\footnotetext{
Department of Pathology, Institute of Basic Medical Sciences, Graduate School of Comprehensive Human Sciences, University of Tsukuba, Tsukuba, Ibaraki, Japan ${ }^{2}$ Ibaraki Prefectural Central Hospital, Kasama, Ibaraki, Japan; ${ }^{3}$ Department of Clinical Pathology, Graduate School of Comprehensive Human Sciences, University of Tsukuba, Tsukuba, Ibaraki, Japan and ${ }^{4}$ Department of Surgery, Institute of Clinical Medicine, Graduate School of Comprehensive Human Sciences, University of Tsukuba, Tsukuba, Ibaraki, Japan

Correspondence: Dr J Kano, PhD, Department of Pathology, Institute of Basic Medical Sciences, Graduate School of Comprehensive Human Sciences, University of Tsukuba, 1-1-1 Tennodai, Tsukuba, Ibaraki 305-8575, Japan. E-mail: junkano@md.tsukuba.ac.jp

Received 09 June 2007; revised 30 October 2007; accepted 01 November 2007
} 
viewpoint of cell biology, it has recently been considered that cancers contain stem-like cells called cancer stem cells that are able to proliferate indefinitely, and that the system of cancer stem cells resembles the system of somatic stem cells in each organ. ${ }^{9}$ Furthermore, somatic stem cells, including adult HSCs, as well as embryonic stem cells, have received widespread attention as possible target cells in regenerative medicine. Therefore, it would be valuable to clarify the features of HSCs and the genes related to hepatic differentiation, not only for prevention or diagnosis of hepatocarcinogenesis, but also for the development of new therapies for hepatocellular carcinomas, and application to regenerative medicine.

We have demonstrated that certain non-parenchymal epithelial cells derived from normal adult porcine liver are bipotent, and that in culture they mimic hepatoblast development in vitro not only morphologically but also functionally. ${ }^{10,11}$ Furthermore, we have established HSLC lines, designated PHeSC-A1 and PHeSC-A2, from the non-parenchymal cell fraction using poly-D-lysine (PDL)-coated dishes with NAIR-1 medium, providing a culture system for investigation of HSCs. ${ }^{12}$ In the present study, we aimed to identify distinctive features of gene expression in adult HSCs, and to investigate whether the genes could be related to hepatic differentiation and regeneration. First, using cultures of PHeSC-A1 cells, we performed suppression-subtractive hybridization (SSH) between HSLCs and hepatocytes to demonstrate differentially expressed genes in HSLCs. We then assessed the expression of the genes in fetal and regenerating livers.

\section{MATERIALS AND METHODS Cells and Culture Conditions}

PHeSC-A1 cells and PHeSC-A2 cells are HSLC lines derived from normal adult porcine liver, and the conditions for their culture have been described previously. ${ }^{12}$ Briefly, they were cultured on PDL-coated 2-well chamber slides (BD Biosciences, Franklin Lakes, NJ, USA) with NAIR-1 medium for 1 month. Their counterparts, porcine hepatocytes, were prepared and cultured for 1 day. Ninety-two percent of the parenchymal fraction in terms of cell number was recognized as hepatocytes on the basis of cell size and morphology (Figure 1a), as reported previously. ${ }^{13}$ Culture conditions for PHeSC-A1 cells and hepatocytes were determined so that cell viability and number were sufficient for the experiments.

\section{Animals}

Normal fifth, seventh and thirteenth gestational week (GW) fetal and adult liver tissues from miniature pigs of the CLAWN strain (Japan Farm CLAWN Institute, Kagoshima, Japan) were used for expression analyses of target genes, employing quantitative real-time reverse transcription-polymerase chain reaction (qRT-PCR), in situ hybridization (ISH) assays or immunohistochemistry (IHC). An $80 \%$

\section{a}

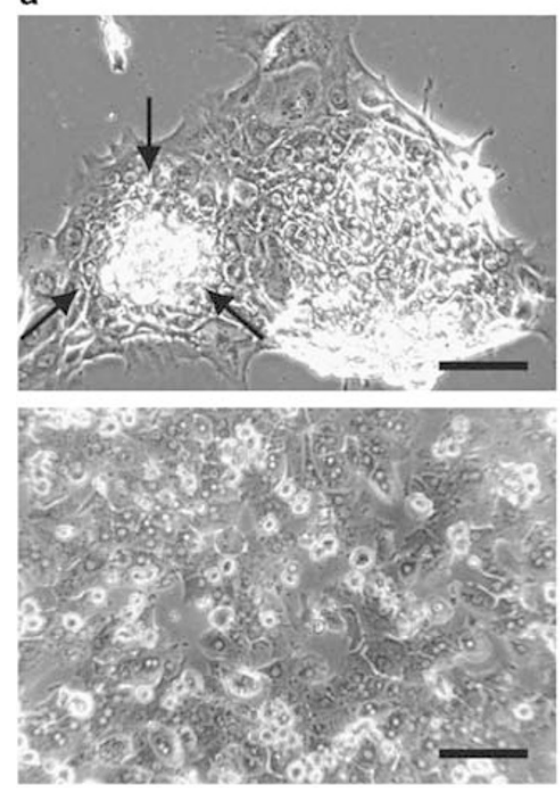

b

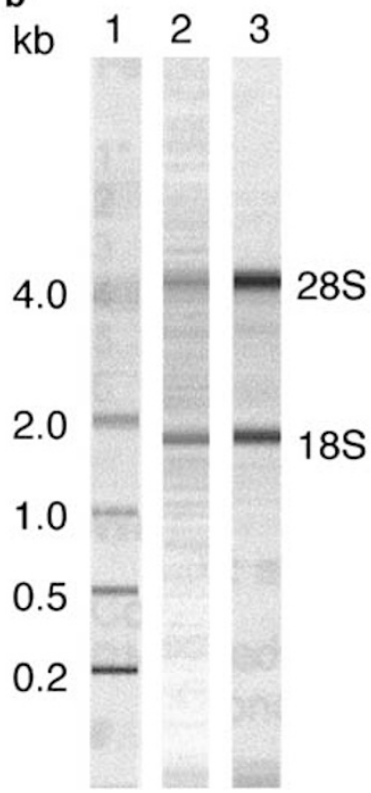

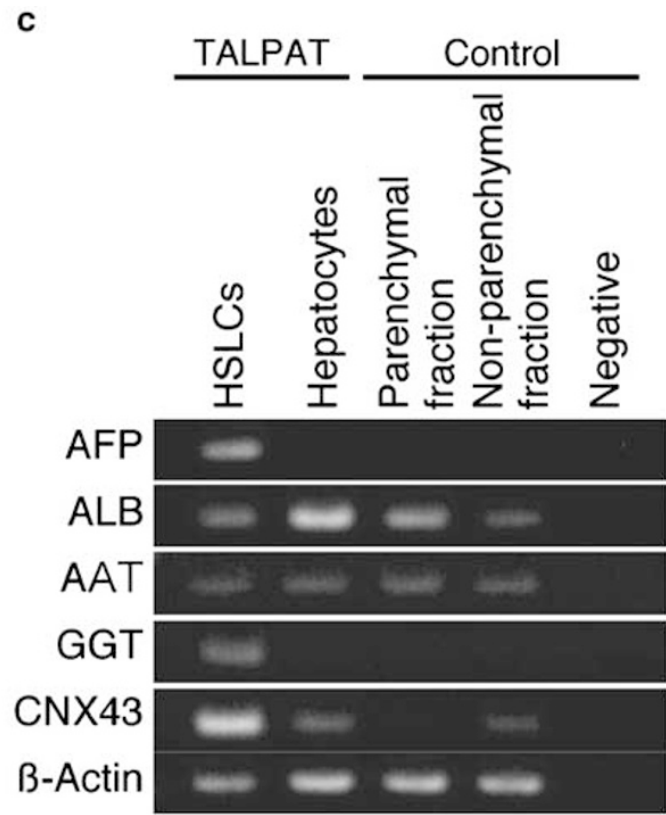

Figure 1 Morphologies of HSLCs and hepatocytes, the mRNA quality of samples and characterization of TALPAT products. (a) Upper panel: phase-contrast photomicrograph of colonies of HSLCs in PHeSC-A1 cell culture. Area surrounded by three arrows was microdissected by LCM. Lower panel: phase-contrast photomicrograph of primary cultured porcine hepatocytes. (b) Electrophoresis patterns of markers (1) and of extracted total RNA from HSLCs (2) and hepatocytes (3). (c) RT-PCR of AFP (hepatoblast marker), albumin (ALB), alpha-1-antitrypsin (AAT) (hepatocyte markers), $\gamma$-glutamyltransferase 1 (GGT) and connexin 43 (CNX43) (cholangiocyte markers) in TALPAT products of HSLCs in PHeSC-A1 culture and hepatocytes. Non-template control is used as a negative control. Scale bars, $50 \mu \mathrm{m}$. 
hepatectomy model (HM) was created following the animal model of liver regeneration described by Wang et al, ${ }^{14}$ with some modifications of the anesthesia protocol. Briefly, three 8 -week-old Landrace White pigs, weighing $25-35 \mathrm{~kg}$, were employed. Food was withheld for about $24 \mathrm{~h}$ preoperatively. Initial sedation was obtained with an intramuscular injection of xylazine $(2 \mathrm{mg} / \mathrm{kg})$ and midazolam $(0.1 \mathrm{mg} / \mathrm{kg})$, and inhalation of $3 \%$ isoflurane with oxygen and nitric oxide at a ratio of 1:1. The pigs were anesthetized by intravenous injection of vecuronium (4 mg per body) and atropine sulfate (one ampule per body), and maintained by endotracheal intubation with inhalation of $2 \%$ isoflurane with oxygen and nitric oxide at a ratio of 1:2. Liver samples were obtained from preoperative liver (Pre), postoperative liver at $1 \mathrm{~h}(1 \mathrm{H})$ when $75 \%$ resection had been performed, after extended hepatectomy of the residual liver up to $80 \%$ resection, and on the seventh day after surgery (7D). All experiments were carried out in a humane manner after receiving approval from the Institutional Animal Experiment Committee of the University of Tsukuba, and in accordance with the Regulation for Animal Experimentations of our university and the Fundamental Guidelines for Proper Conduct of Animal Experiments and Related Activities in Academic Research Institutions under the jurisdiction of the Ministry of Education, Culture, Sports, Science and Technology of Japan.

\section{Laser-Capture Microdissection and RNA Extraction}

PHeSC-A1 cells cultured on chamber slides were stained with Kernechtrot because of the better morphological discrimination of cells and the better extraction of total RNA from laser-capture microdissection (LCM) samples compared with other reagents, based on our pilot experiments. Subsequently, the cells were dehydrated in a graded ethanol series and cleared in xylene. After being dried in a vacuum desiccator for $5 \mathrm{~min}$, HSLC colonies in the PHeSC-Al cell culture were selectively laser-microdissected onto thermoplastic films mounted on optically transparent LCM caps (CapSure ${ }^{\mathrm{TM}}$ Macro LCM Caps LCM0201; Arcturus Engineering Inc., Mountain View, CA, USA) under direct microscopic visualization with a PixCell II Laser-Capture Microdissection System (Arcturus Engineering) operated according to standard protocols (Figure 1). Total RNA from the microdissected cells was isolated with TRIzol reagent (Invitrogen Corp., Carlsbad, CA, USA) in accordance with the manufacturer's instructions. Total RNA from hepatocytes was also isolated directly from the primary culture with TRIzol reagent (Figure 1). The quality of the isolated total RNA was assessed by detection of $28 \mathrm{~S}$ and $18 \mathrm{~S}$ ribosomal RNA with an Agilent 2100 Bioanalyzer (Agilent Technologies, Palo Alto, CA, USA).

\section{Messenger RNA Amplification by TALPAT and Subtraction Analysis by SSH}

To serve as a template for $\mathrm{SSH}$, the messenger RNAs (mRNAs) of HSLCs (PHeSC-Al cells) and hepatocytes were
Table 1 Primer sequences used for amplification

\begin{tabular}{|c|c|}
\hline Gene (accession no.) & $\begin{array}{l}\text { Forward primer }\left(5^{\prime}-3^{\prime}\right) \\
\text { Reverse primer }\left(5^{\prime}-3^{\prime}\right)\end{array}$ \\
\hline \multirow[t]{2}{*}{ Anti-leukoproteinase (NM_213870) } & AAGTCTGCCTCACCCCTGTG \\
\hline & CGTCTGGGAGTGGAAATGGA \\
\hline \multirow[t]{2}{*}{ Matrix Gla protein (NM_214116) } & CGAAAGCCCAAGAGAGAATCC \\
\hline & GCTGCCGGAAATAACGATTG \\
\hline Amyloid- $\beta$ precursor protein & AGCAGATGCAGAACTAGACCGC \\
\hline (NM_214372) & TGCTGAAAGGCGATCATGAG \\
\hline \multirow[t]{2}{*}{ Dickkopf 3 (NM_001039749) } & GCAAAATCATTACCAGCAACTGA \\
\hline & TGAAACAGTCCATGACACCTG \\
\hline \multirow[t]{2}{*}{$\beta$-Actin (AJ312193) } & CTGGACTTCGAGCAGGAGATG \\
\hline & TGTCGACGTCGCACTTCATG \\
\hline \multirow[t]{2}{*}{$\alpha$-Fetoprotein (NM_214317) } & ACAAACCTGAAGGCTTATCTCCAA \\
\hline & TACTGGGACAGCAAGTITAGGATG \\
\hline \multirow[t]{2}{*}{ Albumin (NM_001005208) } & AAAGACTGTCCTGTGCTGAAGACTA \\
\hline & AAGGACTCTGTGCAGCATTG \\
\hline \multirow[t]{2}{*}{$\alpha$-1-antitrypsin (X88780) } & GGAAGCCATCCCCATGTCTA \\
\hline & CCGTTATITTGGGTGGGATT \\
\hline$\gamma$-Glutamyltransferase 1 & GCACCATCAACCTCTACTITGGT \\
\hline (NM_214030) & TCCATCTCATCGTTGAACAGGAT \\
\hline \multirow[t]{2}{*}{ Connexin 43 (AJ293888) } & CCCTCCAAAGACTGTGGATCTC \\
\hline & CTGTCTCCGGTAACCAGCTTGT \\
\hline \multirow[t]{2}{*}{ 18S ribosomal RNA (NR_002170) } & CTTGGATGTGGTAGCCGTTTC \\
\hline & GTCTGCCCTATCAACTTTCGATG \\
\hline
\end{tabular}

amplified from the total RNA isolated by the T7 RNA polymerase promoter-attached, adaptor ligation-mediated and PCR amplification, followed by in vitro T7 transcription (TALPAT) method. ${ }^{15}$ The TALPAT products were characterized by RT-PCR analysis of some hepatic markers using the primers listed in Table 1. SSH was performed with a PCRSelect complementary DNA (cDNA) Subtraction Kit (BD Biosciences Clontech, Mountain View, CA, USA) with some modifications. ${ }^{16}$ Complementary RNA (cRNA) was synthesized from each TALPAT-amplified cDNA. The first-strand cDNA was synthesized according to the TALPAT method, and the second-strand cDNA was synthesized with the cDNA synthesis primer in the kit. Next, SSH was performed according to the manufacturer's instructions. Two-directional (forward and reverse) SSHs and unsubtractive hybridizations were performed between HSLCs and hepatocytes.

\section{Differential Screening of a Subtracted cDNA Library and Sequence Analysis}

The overexpressed cDNA pool from HSLCs (forward subtracted cDNAs) was cloned into the T/A cloning vector $\mathrm{pCR}^{\circledR} 2.1$ (Invitrogen) and transformed into Escherichia coli strain INV $\alpha \mathrm{F}^{\prime}$ (Invitrogen). Individual recombinant (white) 
colonies were picked up and their inserted cDNAs were amplified by PCR as blotted clones for subsequent reverse northern blotting. Differential expression of cloned cDNAs was tested by reverse northern blotting using probes generated by PCR amplification and labeling with $\left[{ }^{32} \mathrm{P}\right] \mathrm{dCTP}$ of both the subtracted and unsubtracted cDNA pools, using a PCR-Select Differential Screening kit (BD Biosciences Clontech). The membranes were exposed to X-ray film (Eastman Kodak Company, Rochester, NY, USA). The clones differentially expressed in HSLCs were selected by visual comparison among dot-blots hybridized with four probes for each clone. The clones differentially expressed in HSLCs were sequenced with a BigDye ${ }^{\circledR}$ Terminator v3.1 Cycle Sequencing Kit (Applied Biosystems Japan Ltd, Tokyo, Japan) and an ABI PRISM 310 Genetic Analyzer (Applied Biosystems). Nucleic acid sequence similarity searches were performed at the National Center for Biotechnology Information (NCBI) using the basic local alignment search tool (BLAST).

\section{Semi-quantitative Screening of Subtracted CDNA Libraries by Virtual Reverse Northern Blotting}

The clones identified by sequence similarity in HSLCs were reblotted onto nylon membranes and re-screened with probes prepared from ${ }^{32} \mathrm{P}$-labeled TALPAT products of HSLCs and hepatocytes. The hybridized membranes were exposed to X-ray films and the signal intensities were evaluated semi-quantitatively with an imaging densitometer (Model GS-700 Imaging Densitometer; Bio-Rad Laboratories, Hercules, CA, USA) relative to the intensity of glyceraldehyde-3-phosphate dehydrogenase. A criterion was set for the selection of genes in further analysis, namely high expression in HSLCs (relative expression >0.5), low expression in hepatocytes (relative expression $<0.1$ ) and a high $\mathrm{S} / \mathrm{H}$ ratio $(>10)$.

\section{qRT-PCR Analysis by SYBR Green I}

Total RNA was prepared from each total culture of PHeSCA1 and PHeSC-A2 cells, hepatocytes and frozen sections of porcine fetal and adult liver tissue with TRIzol reagent, followed by treatment with RNase-free DNase I (Takara Bio, Tokyo, Japan) at $37^{\circ} \mathrm{C}$ for $20 \mathrm{~min}$. The quality of the total RNA samples was assessed with the Agilent 2100 Bioanalyzer as described above. One microgram of total RNA per $100 \mu \mathrm{l}$ reaction mixture was converted to cDNA by using TaqMan ${ }^{\mathrm{TM}}$ Reverse Transcription Reagents with random primers (Applied Biosystems, Roche Molecular Systems, Branchburg, NJ, USA). qRT-PCR was performed with SYBR ${ }^{\circledR}$ Premix Ex $\mathrm{Taq}^{\mathrm{TM}}$ (Perfect Real Time; Takara Bio) on a GeneAmp ${ }^{\circledR}$ 7300 Sequence Detection System (Applied Biosystems) in accordance with the manufacturer's protocol. The primers are listed in Table 1.

\section{Western Blot Analysis}

Protein samples from PHeSC-A1 cells, PHeSC-A2 cells and hepatocytes were prepared with a lysis buffer, M-PER
(PIERCE Biotechnology, Rockford, IL, USA), containing proteinase inhibitors. Total protein aliquots $(20 \mu \mathrm{g}$ protein) were mixed with Laemmli sample buffer, denatured at $95^{\circ} \mathrm{C}$ for $5 \mathrm{~min}$ and separated in a $10 \%$ Tris- $\mathrm{HCl}$ gel (Bio-Rad). Proteins were transferred to polyvinylidene difluoride membranes using an BBlot $^{\mathrm{TM}}$ gel transfer system (Invitrogen). First antibodies used for immunoblotting were rabbit polyclonal anti-human dickkopf-3 (DKK-3; 1:8000, H-130; Santa Cruz Biotechnology, Santa Cruz, CA, USA) and mouse monoclonal anti-chicken $\beta$-actin (1:10000, AC-74; Sigma-Aldrich, St Louis, MO, USA). Protein bands were visualized using SuperSignal ${ }^{\mathbb{R}}$ West Dura extended duration substrate (PIERCE) and X-ray film (BioMax XAR film; Kodak). Recombinant human DKK-3 (2 ng, 1118-DK; R\&D Systems Inc., Minneapolis, MN, USA) was used as a positive control.

\section{ISH Using the Cloned SSH Products as Probes}

The differentially expressed cDNAs, inserted into plasmids, were amplified by PCR with T7 RNA polymerase promoterattached primers. Then the PCR products were transcribed to antisense and sense cRNA probes labeled with digoxygenin (DIG) with a DIG RNA labeling kit (Roche Diagnostics $\mathrm{GmbH}$, Penzberg, Germany) in accordance with the manufacturer's instructions. Formalin-fixed and paraffin-embedded liver tissues were cut into $3-\mu \mathrm{m}$-thick sections and mounted on silane-coated slides (Matsunami Glass Ind. Ltd, Osaka, Japan). Hybridization was performed at $50^{\circ} \mathrm{C}$ for $16 \mathrm{~h}$ in DAKO mRNA in situ hybridization solution (DakoCytomation Inc., Carpinteria, CA, USA) containing either $0.6 \mu \mathrm{g} /$ $\mathrm{ml}$ heat-denatured DIG-labeled antisense probe, the labeled probe with a 50- to 100 -fold excess of the unlabeled probe or the sense probe. Hybridization assays with the last two probes were used as negative controls. Detection of hybridized cRNA probes was performed with horseradish peroxidase-conjugated rabbit anti-DIG antibody (DakoCytomation) and a GenPoint ${ }^{\mathrm{TM}}$ Tyramide signal amplification system (DakoCytomation).

\section{Histology and IHC}

Cultured PHeSC-A1 cells were fixed with 100\% methanol and used for immunochemical analysis. Formalin-fixed, paraffin-embedded sections were used for histopathological and immunochemical analyses. Masson's trichrome staining (MT) and Watanabe's silver impregnation staining (SI) were performed to detect collagen and reticulin fibers in liver tissues. IHC was performed with the DAKO Envision ${ }^{\mathrm{TM}}$ System (DakoCytomation). Sections were pretreated in an autoclave $\left(121^{\circ} \mathrm{C}, 10 \mathrm{~min}\right)$ in $10 \mathrm{mM}$ sodium citrate $(\mathrm{pH} 7.0)$, followed by treatment with $99 \%$ formic acid for $3 \mathrm{~min}$ at room temperature, only in the case of amyloid- $\beta$ precursor protein (APP). The primary antibodies used were rabbit polyclonal anti-human APP (1:2000; Sigma-Aldrich), DKK-3 (1:100, the same antibody as that used in western blot analysis), $\alpha$-fetoprotein (AFP, 1:500; DakoCytomation) and 
mouse monoclonal anti-rat proliferating-cell nuclear antigen (PCNA, 1:1; DakoCytomation). The specificity of the antibody against DKK-3 was confirmed by blocking with recombinant human DKK-3 (1118-DK; R\&D) (Supplementary Figure 1).

Sections were incubated with the first antibody at $4{ }^{\circ} \mathrm{C}$ for $16 \mathrm{~h}$, and the reactants were developed with $3,3^{\prime}$-diaminobenzidine. Normal rabbit and mouse immunoglobulin-G was used as a negative control. PCNA-positive cell numbers per 100 cells in liver tissues were calculated using images of 10 fields per tissue selected randomly, which were captured by a CCD camera with an IPAP-WIN image processor for analytical pathology (Sumika Technoservice Corporation, Osaka, Japan).

\section{Statistical Analysis}

The results were expressed as mean \pm s.e.m. ( $n=3$ experiments assayed in triplicate). Student's $t$-test was performed for statistical evaluation at a significance level of $P<0.05$.

\section{RESULTS}

\section{Templates for SSH}

TALPAT products of HSLCs in PHeSC-A1 cell culture and hepatocytes in primary culture were used as templates for SSH. As described in our previous report, PHeSC-A1 cells showed spontaneous differentiation in a culture system using PDL-coated dishes containing NAIR-1 medium. HSLCs grew into aggregates and differentiated cells grew as a single layer in PHeSC-A1 cell culture. ${ }^{12}$ Therefore, the pure HSLC colonies were picked up selectively by LCM on the basis of their morphology (Figure 1a). The results of electrophoresis on an Agilent 2100 Bioanalyzer confirmed that the sample quality was satisfactory (Figure 1b), and the total RNA samples were used as templates for TALPAT. TALPAT products of HSLC colonies expressed a hepatoblast marker, AFP and some markers of hepatocytes and cholangiocytes, whereas those of hepatocytes did not express AFP (Figure 1c).

\section{Identification of Differentially Expressed Genes in HSLCs} SSH generated a cDNA library of genes that were expressed differentially in HSLCs in comparison with hepatocytes. After

Table 2 Relative expression of clones selected by differential screening and sequence analysis in virtual reverse northern blotting

\begin{tabular}{lll}
\hline Accession no. (gene) & \multicolumn{1}{c}{ Relative expression } & S/H ratio \\
\cline { 3 - 3 } & Stem-like cells $(S) \quad$ Hepatocytes $(H)$ & Picked up clones
\end{tabular}

Known gene

NM_001001266 (metallothionein-1A)

NM_213870 (anti-leukoproteinase)

NM_214116 (matrix Gla protein)

NM_214372 (amyloid- $\beta$ precursor protein)

AY253339 ( $\beta$-GlcNAc $\beta$ 1,4-galactosyltransferase 4)

AF304200 (breed Chinese Meishan mitochondrion genome)

\section{Unknown gene}

DN134418 (NM_001039749: dickkopf-3) ${ }^{\mathrm{a}}$

BX922553 (similar to human kinectin)

CD572500

BQ604650

BQ605000

BX666081

CN159530

BF712408

BX920666

CK466884

No reliable BLAST-matched gene

$\begin{array}{ll}8.53 & 0.42 \\ 2.61 & 0.04 \\ 1.64 & 0.06 \\ 0.67 & 0.05 \\ 0.22 & 0.05 \\ 8.26 & 6.21\end{array}$

0.69

0.29

3.00

0.70

0.64

0.39

0.37

0.30

0.25

0.24

0.32

$\begin{array}{rl}20 & 5 \\ 65 & 2 \\ 27 & 2 \\ 13 & 2 \\ 4 & 1 \\ 1 & 3\end{array}$

BLAST, basic local alignment search tool.

${ }^{\mathrm{a}}$ Full-length sequence of this gene was clarified in this study, and registered as porcine dickkopf-3 (NM_001039749) in NCBI. 
T/A cloning of the library, 186 clones were picked up randomly. Differential screening of these clones selected 39 clones that were expressed differentially in HSLCs. Sequencing and a BLAST search of these clones demonstrated initially that they included six known genes, 10 unknown genes, one unidentified gene and some chimeric fragments (Table 2). NM_001039749 (DKK-3) in Table 2 was identified as a pig EST clone (accession number DN134418), which was similar to part of the $3^{\prime}$ terminal non-coding sequence of human DKK-3. We obtained the full-length cDNA sequence of the EST clone by the $5^{\prime}$-RACE method, and registered this sequence as pig DKK-3 in the DNA Data Bank of Japan (accession number AB232525). The cDNA encoded 349 amino acids and the amino-acid sequence shared about $88 \%$
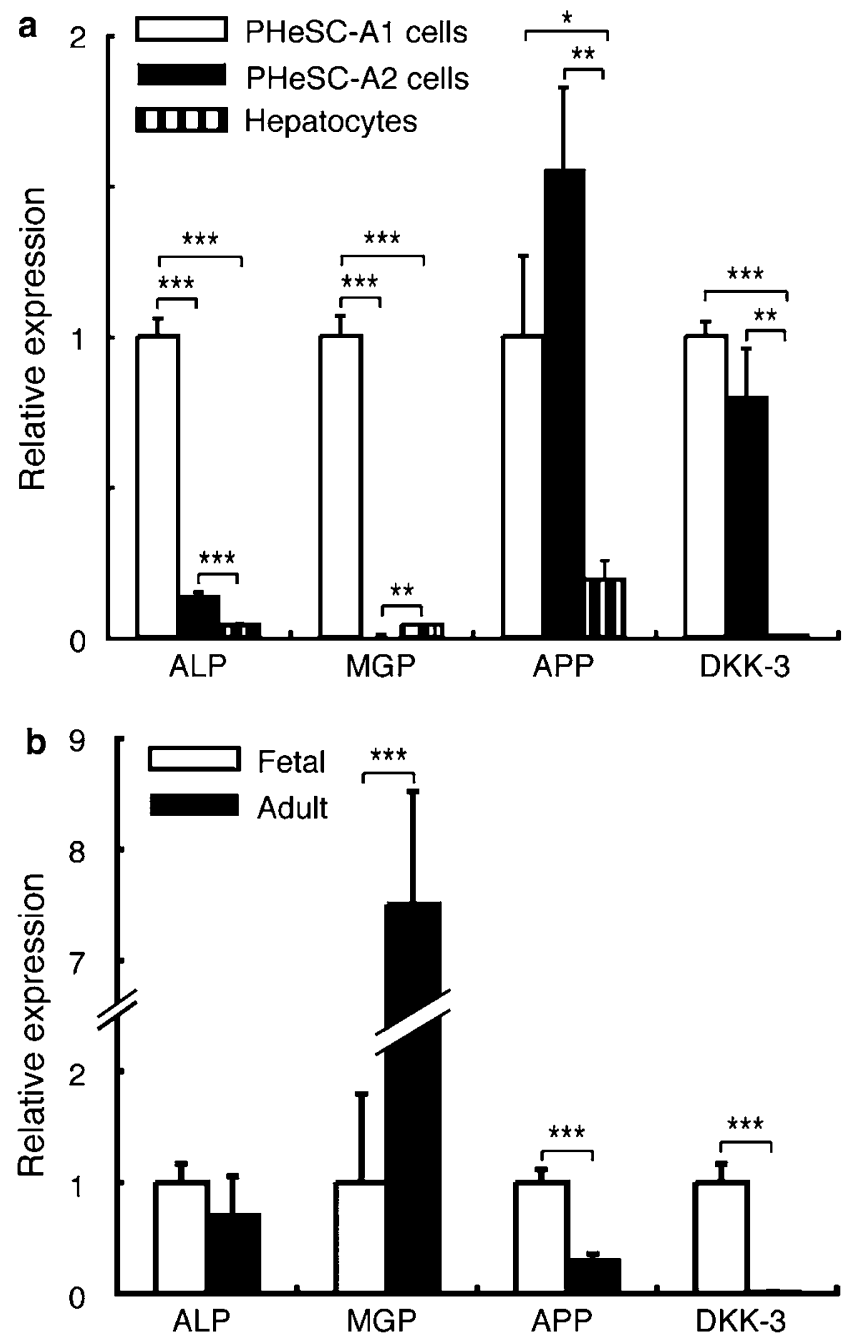

Figure 2 qRT-PCR analysis of expression of ALP, MGP, APP and DKK-3. (a) Shown is the expression in PHeSC-A1 and PHeSC-A2 cells, and mature hepatocytes; (b) shown is the expression in porcine fetal and adult liver tissues. The expression level of each gene is indicated as the amount relative to $\beta$-actin. Data are shown as relative expression level of PHeSC-A1 cells (a) and fetal liver tissues (b) taken as $1 .{ }^{\star} P<0.02 ;{ }^{*} P<0.01$; $* * * P<0.001$. similarity with the product of the human DKK-3 gene. Subsequently, the expression of these clones in HSLCs and hepatocytes was examined by virtual reverse northern blotting with the respective TALPAT products as probes, and the data are summarized in Table 2 as numerical values measured by an imaging densitometer. All genes, except for Chinese Meishan breed mitochondrial genome, were expressed at a higher level in HSLCs than in hepatocytes. To select genes for further analysis, we set a criterion as described in Materials and Methods. It was thought that genes expressed markedly in hepatocytes (relative expression $>0.1$ ), for example, metallothionein-1A, had a possible role in those cells, and therefore that it would be difficult to assess the specificity of such genes in HSLCs. Four genes-anti-leukoproteinase (ALP), matrix Gla protein (MGP), APP and DKK-3 - satisfied the criterion.

\section{qRT-PCR of ALP, MGP, APP and DKK-3 Expression in Hepatic Cells and Liver Tissues}

All the genes were expressed at a significantly higher level in PHeSC-A1 cells and PHeSC-A2 cells, which included the HSLC population, than in mature hepatocytes, except for MGP expressed in PHeSC-A2 cells (Figure 2a). APP and DKK-3 mRNAs were also expressed at a significantly higher level in fifth GW fetal liver, which is the earliest porcine fetal stage characterized by bipotential stem-like cells known as hepatoblasts, than in adult liver. However, there was no
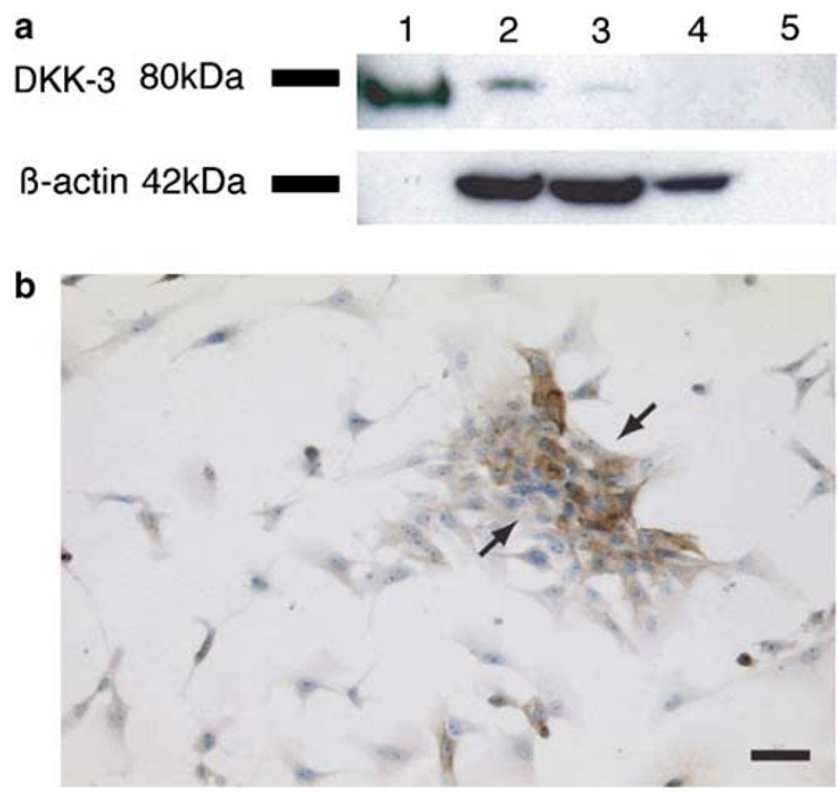

Figure 3 Expression of DKK-3 protein in hepatic cells. (a) Western blot analysis of recombinant human DKK-3 ( $2 \mathrm{ng}$, lane 1, a positive control), PHeSC-A1 cells (lane 2), PHeSC-A2 cells (lane 3 ) and hepatocytes (lane 4). Lane 5 has a non-template control. (b) Immunohistochemistry of DKK-3 in PHeSC-A1 cell culture. Arrows indicate aggregating cells recognized as HSLCs. Cells growing in a monolayer are considered to be spontaneously differentiated cells. Scale bar, $50 \mu \mathrm{m}$. 
marked difference in ALP expression between fetal liver and adult liver. In contrast, MGP expression was significantly lower in fetal liver than in adult liver (Figure 2b).

\section{Expression of DKK-3 Protein in Hepatic Cells}

Western blot analysis demonstrated that PHeSC-A1 cells and PHeSC-A2 cells expressed DKK-3 protein, whereas hepatocytes did not (Figure 3a). IHC of PHeSC-A1 cell culture revealed that DKK-3 protein was expressed in HSLCs growing in aggregates, whereas it was not expressed in most cells growing in a monolayer, which were considered to be spontaneously differentiated cells (Figure $3 b$ ).
ISH of APP and DKK-3 in Fetal and Adult Liver Tissues

It was revealed that APP and DKK-3 were expressed at significantly high levels, not only in HSLCs but also in fifth GW fetal liver tissue, compared with hepatocytes and adult liver tissue, respectively, and their localization in liver tissues was assessed by ISH. In fetal liver, APP expression was very faint, (Figure $4 \mathrm{a}-\mathrm{c}$ ). On the other hand, DKK-3 expression was intense and diffuse in fetal hepatoblasts (Figure $4 \mathrm{~d}-\mathrm{f}$ ). Furthermore, in adult liver, no distinctive expression of APP mRNA was observed, except for faint expression only in the portal area (Figure $4 \mathrm{~g}-\mathrm{i}$ ). Meanwhile, expression of DKK-3 was restricted to certain mesenchymal cells adjacent to intrahepatic bile ducts (Figure 4j-1). The mesenchymal

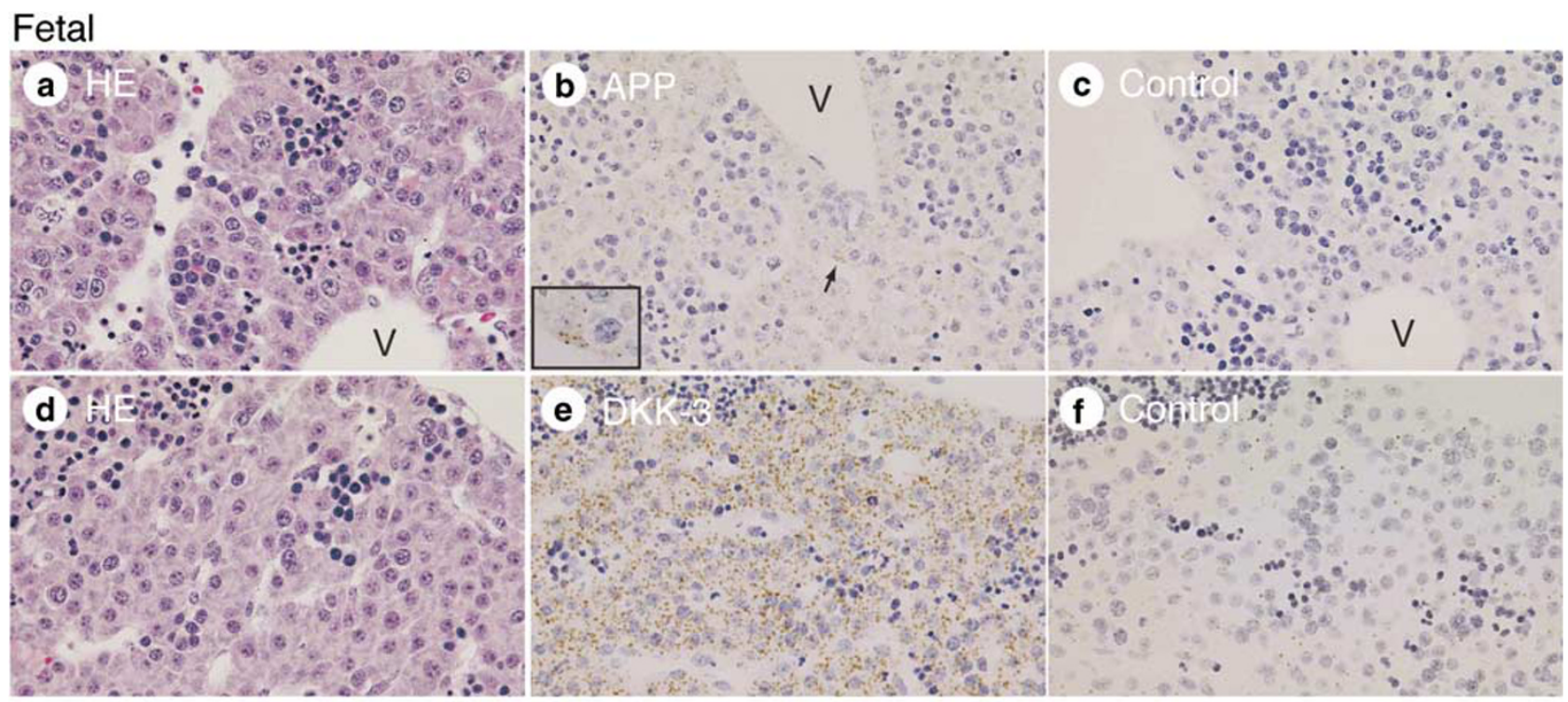

\section{Adult}

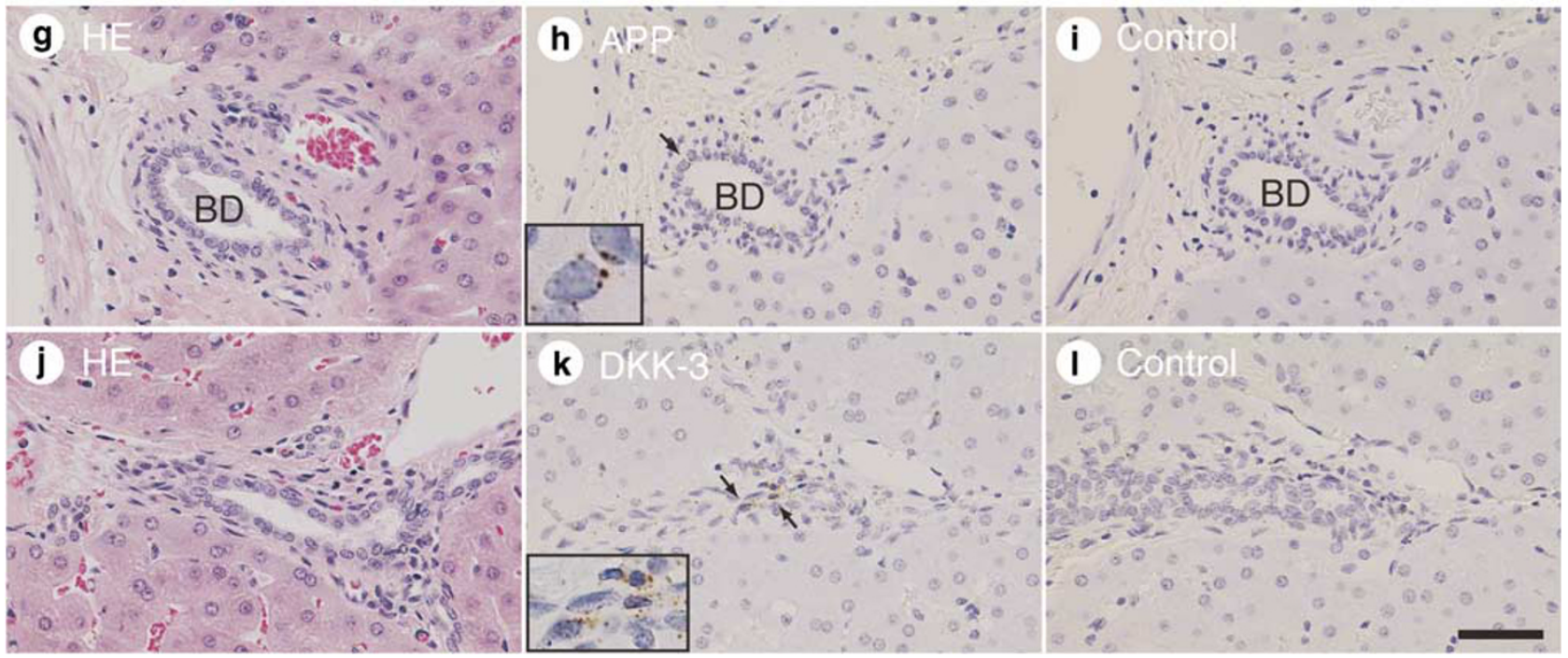

Figure 4 ISH analyses of fetal and adult porcine liver tissues. Fetal liver tissues (a-f) and adult liver tissues ( $\mathbf{g}-\mathbf{l})$. The left column (a, $\mathbf{d}, \mathbf{g}$ and $\mathbf{j})$ shows histology stained by hematoxylin and eosin (HE); the middle column shows APP expression (b, $\mathbf{h}$ ) and DKK-3 expression (e, $\mathbf{k})$ and the right column $(\mathbf{c}, \mathbf{f}, \mathbf{i}$ and $\mathbf{I})$ shows competitive controls. The insets in (b), (h) and (k) are high-magnification images of the corresponding figures indicated by arrows, and typical positive signals (reddish-brown dots). V, vein; BD, bile duct. Scale bar, $50 \mu \mathrm{m}$. 
cells expressing DKK-3 were observed at a very low frequency.

\section{Expression Analysis of APP and DKK-3 in Developing Livers}

Using qRT-PCR in fifth, seventh and thirteenth GW fetal liver tissues, we then investigated whether mRNA expression of APP and DKK-3 changed during the course of liver development. Expression of both APP and DKK-3 was significantly higher in fifth GW fetal liver than at other stages (Figure $5 \mathrm{a}$ and $\mathrm{b}$ ). In contrast, the hepatic markers AFP and ALB were expressed at a significantly low level in fifth GW fetal liver than at other fetal stages, and at the highest level in seventh GW fetal and adult livers, respectively (Figure $5 \mathrm{c}$ and d). Immunohistochemical analysis demonstrated that APP and DKK-3 were present only in fifth GW fetal liver (Figure 6a-1). In fifth GW fetal liver, APP was expressed weakly in the cytoplasm and nuclei of most hepatoblasts (Figure 6e). DKK3 was strongly positive in about $10 \%$ of hepatoblasts, and was weakly expressed in the others (Figure 6i). Results of IHC for protein expression corresponded to those of mRNA expression by ISH. Although no cells expressing CK19 were found
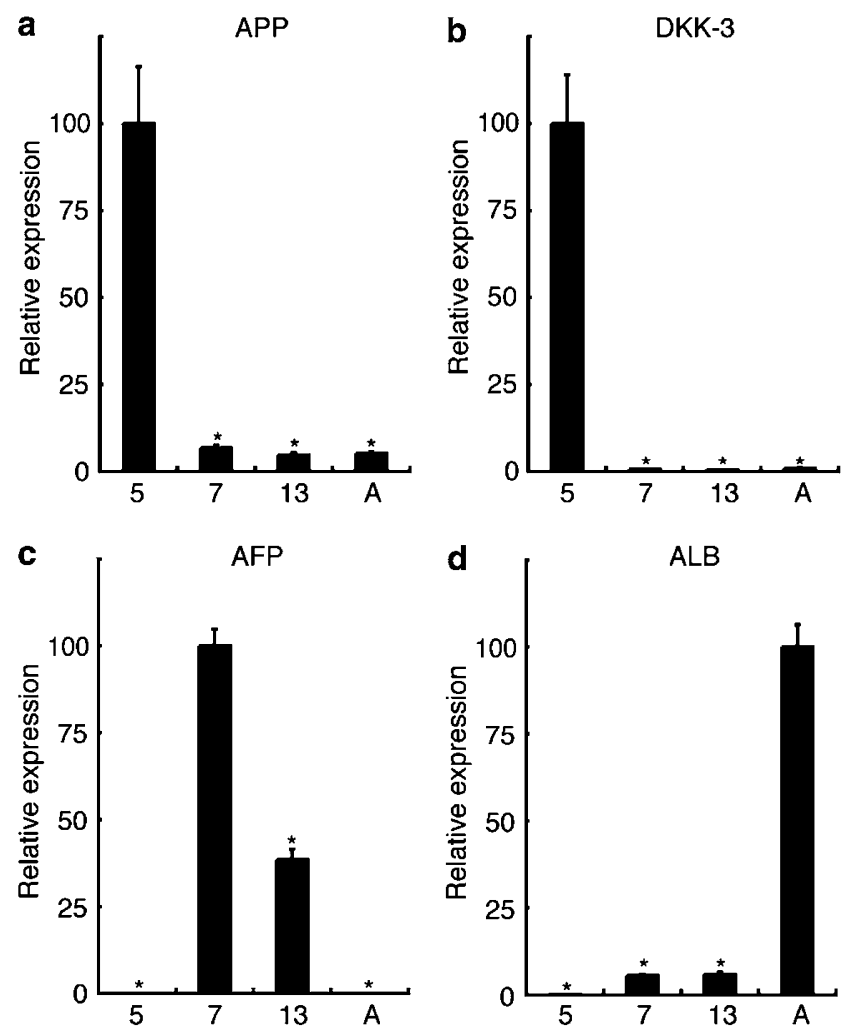

Figure 5 Expression levels of APP, DKK-3, AFP and albumin (ALB) in fifth (5), seventh (7) and thirteenth (13) GW fetal and adult (A) liver tissues by qRT-PCR analysis. The expression level of each gene is indicated as the amount relative to $18 \mathrm{~S}$ ribosomal RNA. Data are shown as relative expression level in fifth GW fetal (a, b), seventh GW fetal (c) and adult liver tissues (d) taken as 100 , respectively. ${ }^{\star} P<0.001$. in fifth GW fetal liver, cells with faint expression were found around veins in seventh GW fetal liver (Figure $6 \mathrm{~m}$ and n). Interlobular bile ducts stained positively with CK19 were observed in thirteenth GW fetal liver, as was the case in adult liver (Figure 6o and p). Histologically, blue-staining fibrous tissue in portal tracts became more distinctive during fetal development, and finally, fibrous septa separated each lobule in normal adult liver (Figure 6q-t). SI also demonstrated that the hepatic parenchyma was occupied by small hepatic cells with poor reticulin fibers in fifth GW fetal liver, but reticulin fibers surrounding hepatic plates became conspicuous as fetal development. One-cell-thick hepatic plates lined by fibers were also found to be complete in normal adult liver (Figure 6u-x).

\section{Expression Analysis of APP and DKK-3 in Regenerative Livers}

qRT-PCR analysis showed that the expression of DKK-3 and AFP was significantly higher in 7D liver than in Pre and $1 \mathrm{H}$ liver. APP was also expressed more highly in 7D liver, but not to a significant degree (Figure $7 \mathrm{a}-\mathrm{c}$ ). In contrast, ALB expression continued to decrease during the experiment (Figure 7d). Immunohistochemical analysis of 7D liver detected DKK-3 in mesenchymal cells in the periportal area, whereas AFP was positive in small hepatic cells in hepatic plates (Figure 8a and $b$ ). In 7D liver, there were more PCNApositive cells than in Pre and $1 \mathrm{H}$ livers (Figure $8 \mathrm{c}$ and e). Histological alteration was also observed among these liver tissues in the liver regeneration model. Blue-stained fibrous tissue completely separated each lobule in Pre liver, but necrotic cells were found in some lobules of $1 \mathrm{H}$ liver, and in 7D liver extension of hepatic sinusoids was observed, whereas fibrous septa became obscure and disappeared (Figure 8e). The result of SI, shown in Figure 8f, demonstrated that small cells with poor reticulin fibers were present in lobules of 7D liver, similar to the situation in fifth GW fetal liver, whereas one-cell-thick hepatic plates lined by fibers remained in lobules of Pre and $1 \mathrm{H}$ livers.

\section{DISCUSSION}

In the present study using the HSLC culture system and SSH, we demonstrated for the first time that 17 clones were differentially upregulated in HSLCs in comparison with hepatocytes. These included 10 unknown genes, representing almost $60 \%$ of genes detected in this analysis (Table 2). We suggest that the high proportion of unknown genes detected in this study was attributable to the slower progress that has been made with analysis of the whole pig genome in comparison with that of the human or mouse genome. Additionally, immature cells might show an expression profile that includes a number of functionally unknown genes. ${ }^{17}$ From the results of further analysis with selected genes-ALP, MGP, APP and DKK-3-(Figure 2), it is suggested that ALP and MGP may not be expressed commonly in adult HSLCs, and may be related to phenotypes derived from an adult 


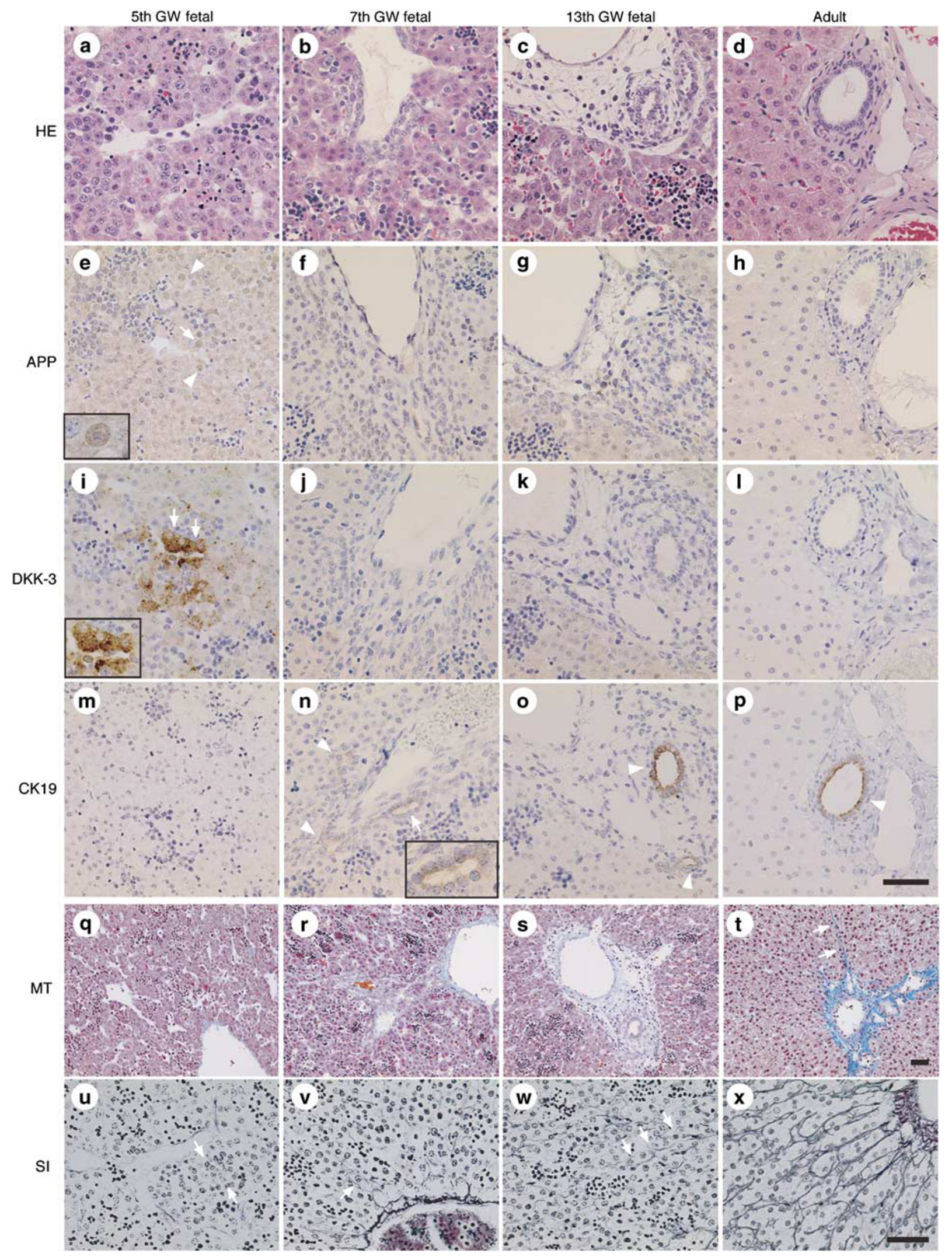


HSLC, because PHeSC-A1 cells and PHeSC-A2 cells are cloned cell lines and differentiate to certain phenotypes spontaneously in culture. ${ }^{12}$

On the other hand, APP and DKK-3 were expressed differentially in adult HSLCs, and also at significantly higher levels in fifth GW fetal liver than in adult liver (Figure 2). Furthermore, ISH analysis showed that APP and DKK-3 were expressed in hepatoblasts, that is, parenchyma, in fifth GW fetal liver, and the expression of these genes appeared to be limited to the periportal area of normal adult liver (Figure 4). This seemed to be consistent with the fact that the HSLCs, PHeSC-A1, were derived from mesenchymal cells of normal adult porcine liver. Fifth GW fetal liver did not express the hepatic markers AFP and ALB (Figure $5 \mathrm{c}$ and d), and had not yet developed intralobular bile ducts and the structure of hepatic plates (Figure $6 \mathrm{~m}-\mathrm{x}$ ). Therefore, fifth GW fetal liver
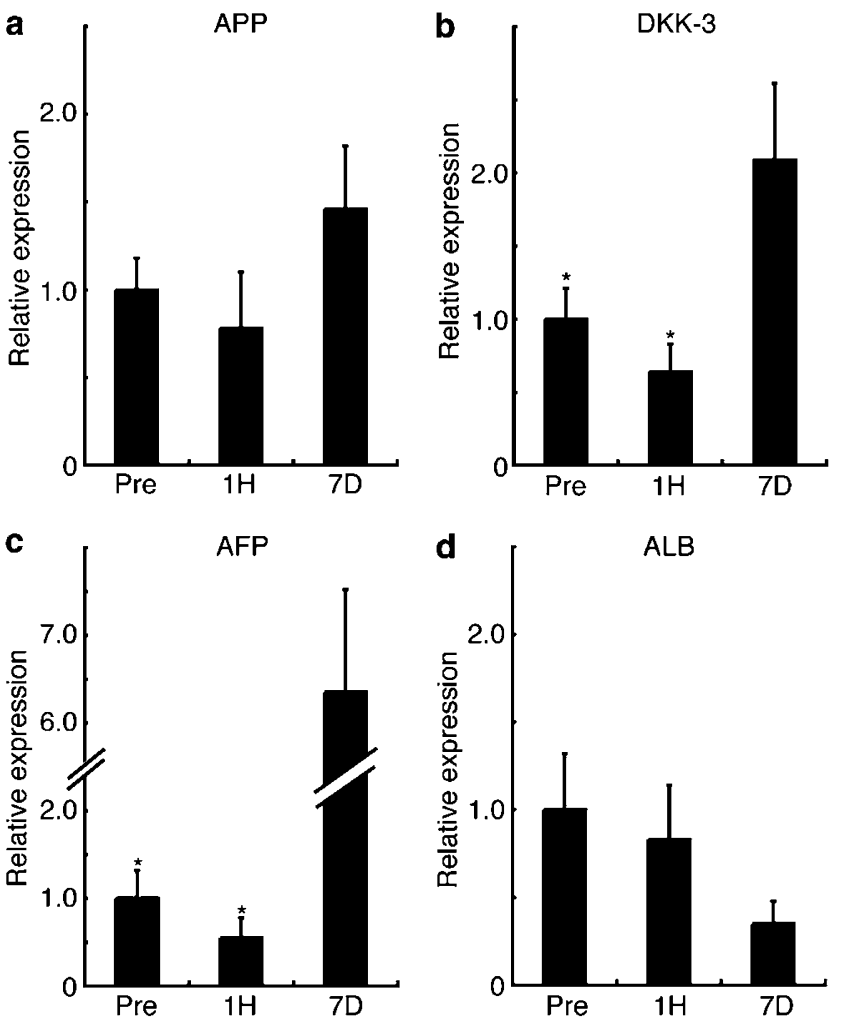

Figure 7 Expression level of APP, DKK3, AFP and albumin (ALB) in Pre, $1 \mathrm{H}$ and on the 7D in the $80 \%$ HM by qRT-PCR analysis. The expression level of each gene is indicated as the amount relative to $18 \mathrm{~S}$ ribosomal RNA. Data are shown as the expression level relative to Pre, taken as $1 .{ }^{\star} P<0.05$. is quite immature, and shows characteristic expression of APP and DKK-3. APP is a well-known precursor of amyloid$\beta$ protein, which is the major component of the amyloid plaques found in Alzheimer's disease. ${ }^{18}$ It has also been reported that APP is processed by $\gamma$-secretase in cells and has transcriptional activity, similar to Notch, which is involved in the differentiation of not only bile duct epithelial cells but also many other tissues. ${ }^{19-21}$ Their functional interaction has been suggested in neurons. ${ }^{22}$ Because APP protein was detected in not only most of the cytoplasm, but also some nuclei of cells in fifth GW fetal liver (Figure 6e), it may act as a transcriptional factor in liver at this stage. On the other hand, DKK-3 belongs to the DKK family, which is thought to inhibit the Wnt-signaling pathway. ${ }^{23}$ Because DKK-3 does not bind effectors that have avidity for DKK-1, -2 and -4 , and the inhibitory effect of DKK-3 on the Wnt-signaling pathway has not been clarified, DKK-3 is thought to be a divergent member of the DKK family. ${ }^{24}$ Recently, DKK-3 was reported to show spatial expression during development of organs such as the adrenal cortex and teeth. ${ }^{24-27}$ Byun and co-workers demonstrated that in normal human tissues, DKK-3 was expressed more intensely in the deep gastric glands/colonic crypt bases, where gastrointestinal stem cells reside. ${ }^{28}$ DKK-3 is also designated REIC (Reduced Expression in Immortalized Cells), and has been shown to be downregulated in tumor cells and to influence the malignancy and apoptosis of tumor cells. ${ }^{29-32}$ The results of the above studies have led to a hypothesis that DKK-3 participates in cellular development, differentiation and growth, whereas no previous study has suggested that DKK-3 is related to the differentiation of HSLCs. Most recently, Hermann et $a l^{33}$ revealed that DKK-3 was present in a subset of beta cells in the human pancreas, and other studies have demonstrated trans-differentiation of adult HSLCs into pancreatic endocrine cells. ${ }^{34,35}$ These previous findings and the present results suggest that DKK-3 may play a role in such transdifferentiation and tissue and cell regeneration in the pancreas and liver.

The role of HSCs in liver regeneration has not been clear, but in $80 \%$ HM the mRNA expression of DKK-3 and AFP was significantly higher in 7D liver than Pre and $1 \mathrm{H}$ livers (Figure $7 \mathrm{~b}$ and c). Interestingly, IHC in 7D liver revealed that cells expressing DKK-3 were mesenchymal cells in the periportal area, while cells expressing AFP were parenchymal small liver cells (Figure 8a and b), suggesting that cells expressing DKK-3 and AFP have different localization and show different phenotypes. Taken together with the time lag

Figure 6 Immunohistochemical and histological analyses of fetal and adult liver tissues. The left column (a, e, i, $\mathbf{m}, \mathbf{q}$ and $\mathbf{u})$ shows fifth GW fetal liver. The left-middle column ( $\mathbf{b}, \mathbf{f}, \mathbf{j}, \mathbf{n}, \mathbf{r}$ and $\mathbf{v})$ shows seventh GW fetal liver. The right-middle column $(\mathbf{c}, \mathbf{g}, \mathbf{k}, \mathbf{o}, \mathbf{s}$ and $\mathbf{w})$ shows thirteenth GW fetal liver. The right column (d, h, I, p, $\mathbf{t}$ and $\mathbf{x}$ ) shows adult liver tissues. (a-d) HE, (e-h) APP, (i-l) DKK-3, (m-p) cytokeratin 19 (CK19), (q-t) MT and (u-x) Watanabe's SI. The insets in (e), (i) and (n) are high-magnification images of the corresponding figures indicated by arrows, and arrows and arrowheads in (e), (i), (n), (o) and (p) indicate typical positive signals. Arrows in (t) indicate fibrous septa. Arrows in (u) indicate small hepatic cells with poor reticulin fibers, and those in (v) and $(\mathbf{w})$ indicate reticulin fibers surrounding hepatic plates. Original magnifications of $(\mathbf{a}-\mathbf{p}),(\mathbf{q}-\mathbf{t})$ and $(\mathbf{u}-\mathbf{x})$ are the same. Scale bars, $50 \mu \mathrm{m}$. 
a

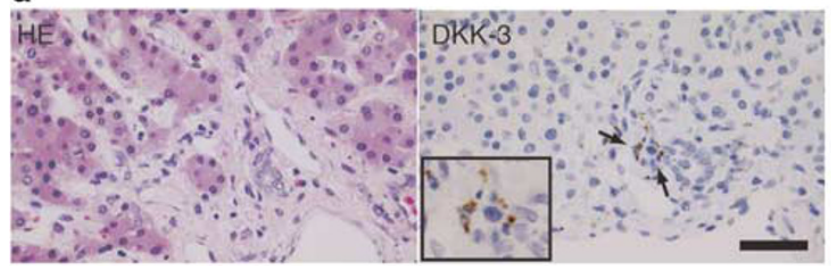

C

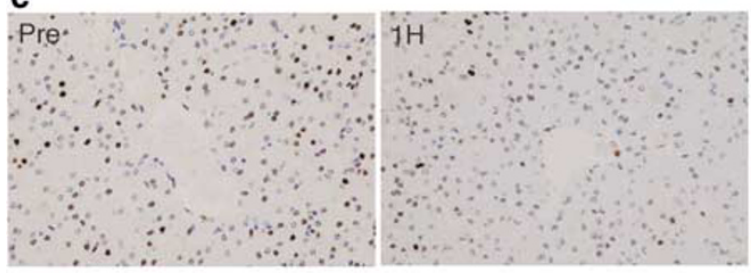

e
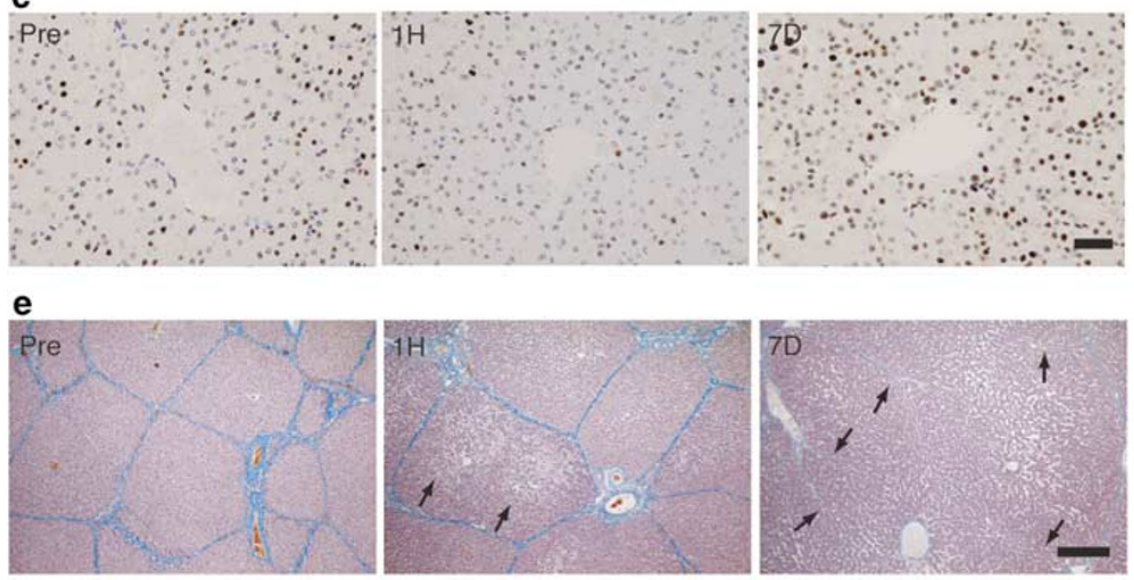

f

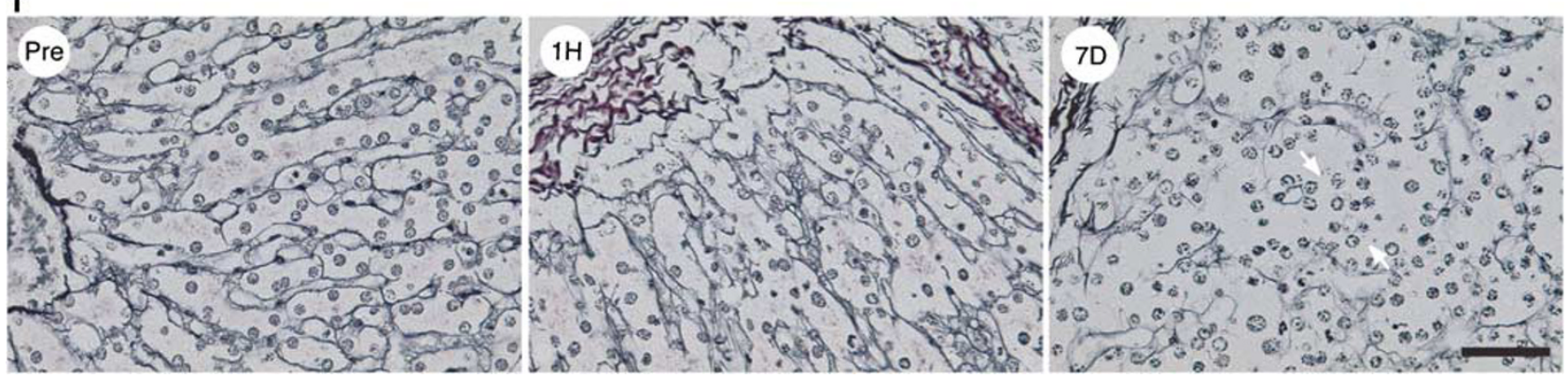

Figure 8 Immunohistochemical and histological analyses of Pre1H and on the 7D in the 80\% HM. (a) DKK-3 expressed in mesenchymal cells in the periportal area, and (b) AFP expressed in small hepatic cells in hepatic plates in 7D liver. The insets are high-magnification images indicated by arrows. Scale bars, $50 \mu \mathrm{m}$. (c) More PCNA-positive cells are observed in 7D liver than in Pre and 1H livers. Scale bar, $50 \mu \mathrm{m}$. (d) Number of PCNA-positive cells per 100 cells is highest in 7D liver in the $80 \% \mathrm{HM} .{ }^{\star} P<0.05$. (e) Blue-stained fibrous tissues completely separate each lobule in Pre and $1 \mathrm{H}$ livers. Necrotic cells are present in the same lobules of $1 \mathrm{H}$ liver (arrows). Extension of hepatic sinusoids is observed, but the fibrous septa have become obscure and disappeared in 7D liver (arrows) (MT) Scale bar, $500 \mu \mathrm{m}$. (f) One-cell-thick hepatic plates lined by fibers are retained in lobules of Pre and 1H livers, and small cells with poor reticulin fibers are evident in lobules of 7D liver (arrows) (SI). Scale bar, $50 \mu \mathrm{m}$.

between the expression of the two genes in fetal livers, mesenchymal cells in the portal area expressing DKK-3 are suggested to be less differentiated than small hepatocytes expressing AFP in the liver. Based on the data for PCAN expression and MT and SI staining in livers of 80\% HM, 7D liver, in which DKK-3 was upregulated, was considered to be in the process of rapid growth, and similar to fifth GW fetal liver histologically (Figure $8 \mathrm{c}-\mathrm{f}$ ). These results suggest that cells expressing DKK-3 may play a role in liver regeneration. Further studies of liver regeneration using DKK-3 knockout mice will be needed to clarify the role of DKK-3.

In conclusion, we have demonstrated for the first time that APP and DKK-3 are differentially expressed in adult HSLCs. The expression of APP and DKK-3 in the liver was characteristically higher at a very early fetal stage than in the intermediate or late stage, or in adult livers, and was inversely correlated with the expression of AFP and ALB. These results suggested that APP and DKK-3 were upregulated in immature and developing liver, and possibly involved in hepatic differentiation. Moreover, DKK-3, like AFP, was upregulated in 7D liver of $80 \% \mathrm{HM}$, which was shown to be proliferating and to have similar developing histology to fifth GW fetal liver, suggesting that DKK-3 was also involved in liver regeneration. Cells expressing DKK-3 were located in the hepatic parenchyma of fifth GW fetal liver, and in the periportal area of normal and regenerating adult liver, suggesting the possible presence of adult HSLCs in the periportal area. These findings add new perspectives to the mechanism of hepatic differentiation and the presence of HSCs in adult liver. Our data are also relevant to the nature of HSLC 
induction in periportal areas when liver insults such as alcohol abuse or viral infection stimulate liver regeneration. Lineage tracing and functional analyses of DKK-3 in fetal liver and regenerating liver will help to clarify the relationship between HSLCs and non-parenchymal cells expressing the gene in adult liver, and the functions of the gene in hepatic development and differentiation.

Supplementary Information accompanies the paper on the Laboratory Investigation website (http://www.laboratoryinvestigation.org)

\section{ACKNOWLEDGEMENT}

We are grateful to Dr Kazuhiko Aoyagi and Dr Gen Fujii (National Cancer Center Research Institute, Tokyo) and Ms Lisa Roller (Rush Medical School, Chicago, USA) for helpful technical advice and assistance. This work was supported in part by Grants-in-Aid for Scientific Research from the Ministry of Education, Culture, Sports, Science, and Technology of Japan (nos. 14570178 and 17590335 ) to $\mathrm{JK}, \mathrm{TI}$ and MN.

1. Yasui O, Miura N, Terada $\mathrm{K}$, et al. Isolation of oval cells from LongEvans Cinnamon rats and their transformation into hepatocytes in vivo in the rat liver. Hepatology 1997;25:329-334.

2. Alison M, Sarraf C. Hepatic stem cells. J Hepatol 1998;26:676-682.

3. Lazaro CA, Rhim JA, Yamada Y, et al. Generation of hepatocytes from oval cell precursors in culture. Cancer Res 1998;58:5514-5522.

4. Mitaka T. Reconstruction of hepatic organoid by hepatic stem cells. J Hepatobiliary Pancreat Surg 2002;9:697-703.

5. Alison MR, Vig P, Russo $F$, et al. Hepatic stem cells: from inside and outside the liver? Cell Prolif 2004;37:1-21.

6. Bryon E, Grossbard B, Hatch $\mathrm{H}$, et al. Mouse A6-positive hepatic oval cells also express several hematopoietic stem cell markers. Hepatology 2003;37:632-640.

7. Tanimizu N, Nishikawa M, Saito $\mathrm{H}$, et al. Isolation of hepatoblasts based on the expression of Dlk/Pref-1. J Cell Sci 2003;116:1775-1786.

8. Suzuki $A$, Zheng $Y$, Kondo $R$, et al. Flow-cytometric separation and enrichment of hepatic progenitor cells in developing mouse liver. Hepatology 2000;32:1230-1239.

9. Reya T, Morrison SJ, Clarke MF, et al. Stem cells, cancer, and cancer stem cells. Nature 2001;414:105-111.

10. Kano J, Tokiwa T, Zhou X, et al. Colonial growth and differentiation of epithelial cells derived from abattoir adult porcine livers. J Gastroenterol Hepatol 1998;3(Suppl):S62-S69.

11. Kano J, Noguchi $M$, Kodama $M$, et al. The in vitro differentiating capacity of nonparenchymal epithelial cells derived from adult porcine livers. Am J Pathol 2000;56:2033-2043.

12. Kano J, Ishiyama $\mathrm{T}$, Nakamura $\mathrm{N}$, et al. Establishment of hepatic stemlike cell lines from normal adult porcine liver in a poly-D-lysine-coated dish with NAIR-1 medium. In Vitro Cell Dev Biol Anim 2003;39:440-448.

13. Zhou $X$, Tokiwa $T$, Kano J, et al. Isolation and primary culture of adult pig hepatocytes. Methods Cell Sci 1998;19:277-284.

14. Wang HS, Ohkohchi N, Enomoto Y, et al. Effect of portocaval shunt on residual extreme small liver after extended hepatectomy in porcine. World J Surg 2006;30:2014-2022.

15. Aoyagi $K$, Tatsuta T, Nishigaki M, et al. A faithful method for PCRmediated global mRNA amplification and its integration into microarray analysis on laser-captured cells. Biochem Biophys Res Commun 2003;300:915-920.

16. Okubo C, Morishita Y, Minami $Y$, et al. Phenotypic characteristics of mouse lung adenoma induced by 4-(methylnitrosoamino)-1-(3-pyridyl)1-butanone. Mol Carcinog 2005;2:121-126.

17. Ramalho-Santos M, Yoon S, Matsuzaki $Y$, et al. 'Stemness': transcriptional profiling of embryonic and adult stem cells. Science 2002;298:597-600.

18. Wolfe MS. APP, Notch, and presenilin: molecular pieces in the puzzle of Alzheimer's disease. Int Immunopharmacol 2002;2:1919-1929.

19. McCright B, Lozier J, Gridley T. A mouse model of Alagile syndrome: Notch2 as a genetic modifier of Jag1 haploinsufficiency. Development 2002;129:1075-1082.

20. Tanimizu N, Miyajima A. Notch signaling controls hepatoblast differentiation by altering the expression of liver-enriched transcription factors. J Cell Sci 2004;117(Part 15):3165-3174.

21. Berezovska O, Jack C, Deng A, et al. Notch1 and amyloid precursor protein are competitive substrates for presenilin1-dependent gammasecretase cleavage. J Biol Chem 2001;276:30018-30028.

22. Merdes G, Soba $P$, Loewer $A$, et al. Interference of human and Drosophilla APP and APP-like proteins with PNS development in Drosophilla. EMBO J 2004;23:4082-4095.

23. Krupnik VE, Sharp JD, Jiang C, et al. Functional and structural diversity of the human Dickkopf gene family. Gene 1999;238:301-313.

24. Niehrs C. Function and biological roles of the Dickkopf family of Wnt modulators. Oncogene 2006;25:7469-7481.

25. Suwa $T$, Chen $M$, Hawks $C L$, et al. Zonal expression of dickkopf-3 and components of the Wnt signaling pathways in the human adrenal cortex. J Endocrinol 2003;178:149-158.

26. Field $K$, Kettunen $P$, Furmanek $T$, et al. Dynamic expression of Wnt signaling-related Dickkopf1, -2 , and -3 mRNAs in the developing mouse tooth. Dev Dyn 2005;58:161-166.

27. Nie X. Dkk1, -2 and -3 expression in mouse craniofacial development. J Mol Histol 2005;36:367-372.

28. Byun $\mathrm{T}$, Karimi $\mathrm{M}$, Marsh $\mathrm{JL}$, et al. Expression of secreted Wnt antagonists in gastrointestinal tissues: potential role in stem cell homeostasis. J Clin Pathol 2005;233:161-166.

29. Tsuji T, Miyazaki M, Sakaguchi $M$, et al. REIC gene shows downregulation in human immortalized cells and human tumor-derived cell lines. Biochem Biophys Res Commun 2000;268:20-24.

30. Hoang BH, Kubo $\mathrm{T}$, Healey $\mathrm{JH}$, et al. Dickkopf 3 inhibits invasion and motility of Saos-2 osteosarcoma cells by modulating the Wnt- $\beta$ catenin pathway. Cancer Res 2004;64:2734-2739.

31. Roman-Gomez J, Jimenez-Velasco A, Agirre X, et al. Transcriptional silencing of the Dickkopfs-3 (Dkk-3) gene by CpG hypermethylation in acute lymphoblastic leukaemia. Br J Cancer 2004;91:707-713.

32. Abarzua $F$, Sakaguchi $M$, Takaishi $M$, et al. Adenovirus-mediated overexpression of REIC/Dkk-3 selectively induces apoptosis in human prostate cancer cells through activation of c-Jun-NH2-kinase. Cancer Res 2005;65:9617-9622.

33. Hermann M, Pirkebner D, Draxl A, et al. Dickkopf-3 is expressed in a subset of adult human pancreatic beta cells. Histochem Cell Biol 2007;127:513-521.

34. Yang L, Li S, Hatch $\mathrm{H}$, et al. In vitro trans-differentiation of adult hepatic stem cells into pancreatic endocrine hormone-producing cells. Proc Natl Acad Sci USA 2002;99:8078-8083.

35. Yamada S, Terada K, Ueno $\mathrm{Y}$, et al. Differentiation of adult hepatic stem-like cells into pancreatic endocrine cells. Cell Transplant 2005;14:647-653. 